\title{
Imagens de natureza nos jornais Folha de $S$. Paulo e O Estado de S. Paulo
}

\section{Images of nature in the newspapers Folha de S. Paulo and O Estado de S. Paulo}

\author{
Gislene Silva \\ Programa de Pós-Graduação em Jornalismo da Universidade Federal de Santa Catarina, Florianópolis, SC, Brasil \\ ORCID: 0000-0002-8105-5024 \\ <gislenedasilva@gmail.com>
}

\section{Como citar este artigo (How to cite this article):}

SILVA, Gislene. Imagens de natureza nos jornais Folha de S. Paulo e O Estado de S. Paulo. Revista Famecos, Porto Alegre, v. 25, n. 3 p. 1-20, setembro, outubro, novembro e dezembro de 2018: ID29126. DOI: http://dx.doi.org/10.15448/1980-3729.2018.3.29126.

\section{RESUMO}

Inserido no campo da produção e circulação de sentidos pela mídia e na abordagem do fenômeno jornalístico a partir de estudos do imaginário, o artigo toma como objeto de análise as imagens de natureza em textos jornalísticos impressos. Como metodologias, adotou-se, pela perspectiva epistemológica, a combinação adaptada de dois métodos de Gilbert Durand, a mitocrítica e a mitanálise. Pela perspectiva operacional, tomaram-se como objeto empírico as edições impressas de dois jornais diários de circulação nacional, Folha de S. Paulo (1995 -2012) e O Estado de S. Paulo (1995-2012). Não foi feita distinção entre editorias e nem entre gêneros jornalísticos, observando imagens de natureza presentes nas mais diversas situações noticiosas, fossem em matéria de economia ou turismo, notícia curta, artigo assinado ou editorial. No total, 915 unidades noticiosas foram trabalhadas qualitativa e quantitativamente. A investigação pretendeu visualizar conjuntos de imagens na imprensa brasileira que estão orientando ou expressando, nas últimas três décadas, o pensamento da sociedade brasileira a respeito da natureza, do mundo natural.

\begin{abstract}
Situated within the field of production and circulation of meaning by the media, and approaching the journalistic phenomenon through studies of the imaginary, this article has focused on images of nature in print journalism. The chosen methodology was an adapted combination of Gilbert Durand's two methods, mitochristic and mitoanalysis - adopted from an epistemological perspective. The empirical object are printed editions of two national daily newspapers, Folha de S. Paulo (1995 -2012) and O Estado de S. Paulo (1995-2012). While observing images of nature presented in diverse news situations, no distinctions have been made between editorial sections or genres - whether in economics, tourism, short stories, signed articles or editorials. The total of 915 news units have been analyzed, both qualitatively and quantitatively. The research has attempted to visualize sets of images orienting or expressing Brazilian society's thinking about nature in the last three decades.
\end{abstract}

Keywords: Imaginary. Nature. News coverage.

Palavras-chave: Imaginário. Natureza. Cobertura jornalística.

\section{Notas iniciais}

Este estudo toma como objeto de análise as imagens de natureza em textos jornalísticos impressos, pelo caminho das articulações transdisciplinares entre os campos da Antropologia, Sociologia e Jornalismo. E tem como objetivo visualizar na imprensa alguns conjuntos de imagens que estão orientando ou 
expressando, nas últimas três décadas, o pensamento da sociedade brasileira a respeito da natureza, do mundo natural. Tal como algumas abordagens sociológicas e antropológicas, interessa neste estudo de jornalismo a dimensão imaginária das atividades humanas, mais especificamente a investigação sobre a circulação de imaginários na mídia noticiosa e, neste artigo, sobre imagens de natureza na imprensa escrita.

Parto de alguns pressupostos que já vêm sustentando trabalhos anteriores que desenvolvi. E preciso repassá-los aqui antes de apresentar a pesquisa realizada sobre imagens de natureza nas edições impressas de dois jornais diários de circulação nacional, Folha de S. Paulo (1995-2012) e O Estado de S. Paulo (1995-2012).

Primeiramente, o pressuposto de que há manifestações sensíveis e emocionais, simbólicas e míticas do mundo imaginário que estão presentes rotineiramente nas temáticas diversas da cobertura jornalística e que devem ser levadas em conta pela Teoria do Jornalismo (Silva, G., 2010).

Depois, o de que, ao tratar de imagens arquetípicas, metáforas de base, imagens-matrizes, a imagem seja compreendida como modalidade sensorial e manifestação sensível do abstrato ou do invisível - algo próximo de imagem literária, afetada pela psique, pelo consciente e inconsciente, pelos devaneios e sonhos, e não apenas como imagem pictórica, acoplada a suportes iconográficos.

Outra premissa vem de uma explicitação de Michel Maffesoli: "Não é a imagem que produz o imaginário, mas o contrário. A existência de um imaginário determina a existência de um conjunto de imagens. A imagem não é o suporte, mas o resultado" (Maffesoli, 2001, p. 76). Em complementação, trago a observação, feita por Juremir Machado Silva, de que o imaginário deve sempre ser entendido como algo mais amplo que um conjunto de imagens. "O imaginário é uma rede etérea e movediça de valores e sensações partilhadas concreta ou virtualmente" (Silva, J. M., 2006, p. 9). O imaginário não seria um mero álbum de fotografias mentais nem um museu da memória individual ou social. Nem se restringiria ao exercício artístico da imaginação sobre o mundo. Tampouco, nas palavras de Legros e coautores, seria

uma forma social escondida, secreta, inconsciente que vive sob as fibras do tecido social. Ele não é o reflexo, o espelho deformado, o mundo revirado ou a sombra da realidade, uma sociedade subterrânea que cruzará profundamente os esgotos da vida cotidiana, mas ele estrutura, no fundo, o entendimento humano (Legros e outros, 2007, p. 111). 
Como quarto pressuposto, o entendimento de que os sentimentos, a memória e as produções simbólicas excedem a esfera do individual e do privado e se estendem para os domínios sociais, coletivos. O imaginário circula, então, através da história, das culturas e dos grupos sociais, como um fenômeno coletivo, social e histórico (Legros e outros, 2007, p. 10). Portanto, na relação entre imaginário e jornalismo interessa o aspecto coletivo, a manifestação social do imaginário, uma vez que o fenômeno da comunicação noticiosa é de natureza igualmente social e coletiva.

$\mathrm{E}$, além de coletivo, o imaginário transita no tempo, entre passado e futuro. Nos termos de J. M. Silva (2006, p. 9, 11 e 12), ele seria reservatório e motor. Como reservatório, o imaginário agregaria imagens, sentimentos, lembranças, experiências, visões do real, leituras de vida e, através de um mecanismo individual/grupal, sedimentaria um modo de ver, de ser, de agir, de sentir e de estar no mundo. Como motor, elemento propulsor, o imaginário retorna ao real, seria um sonho que realiza a realidade, funcionando como catalisador, estimulador e estruturador das práticas. Assim, afirma o autor, todo indivíduo submete-se a um imaginário preexistente e todo sujeito é um inseminador de imaginários (Silva, J. M., 2006, p. 9, 11 e 12).

E ainda em termos de ordem temporal, para Durand, o imaginário, longe de aparecer como um momento ultrapassado na evolução da espécie, manifesta-se como elemento constitutivo e instaurativo do comportamento específico do Homo sapiens (Durand, 1997, p. 429). Além disso, o imaginário não é tomado aqui como categoria antitética do racional, uma vez que ambos pertencem ao universo das imagens. O imaginário não seria nem abstrato nem concreto, nem racional nem irracional, ele é sempre ambos (Silva, G., 2009, p. 213). Esta compreensão nos leva a tomar as notícias como um exercício de produção de sentido e de entendimento do mundo que responde não só a demandas pragmáticas - apreender a realidade objetiva e rotineira - mas também a demandas subjetivas - nos elevar "para além do imediato diário" e nos situar "dentro de 'imensos edifícios de representação simbólica"' (Silva, G. 2005, p. 101). Maffesoli entende que os jornalistas estão cada vez mais atentos a estas questões da trama social e seu cotidiano,

concedendo, ao lado de rubricas políticas, econômicas, um lugar não negligenciável às chamadas "ocorrências" (fr. "faits divers"). Eu diria que, para além dos simples clichês jornalísticos, convém dar um estatuto teórico a esse conjunto de 'ocorrências'. Isso pode ser feito se à observação for concedida a dignidade que lhe é de direito (Maffesoli, 1998, p. 123 -124). 
Por fim, como mais um dos pressupostos, o entendimento de que o jornalismo não deve ser tratado somente como uma força conservadora e inercial, associando as simbologias-míticas presentes no noticiário a um dispositivo de criação de consensos, de fechamento de sentidos e de afirmação das visões de mundo vigentes (Silva, G.; Maia, F. D., 2011). Diferentemente, a opção desta pesquisa se fundamenta no potencial da simbologia mítica para atuar em processos de transformações socioculturais e históricos.

\section{Natureza: perspectiva teórico-epistemológica}

Tais como os estudos do imaginário de forma geral, também os estudos das imagens de natureza que povoam a vida em sociedade passam por dimensões sensíveis ou afetivas e, igualmente, não escapam das clivagens do tempo em que se vive. Keith Thomas, em O homem e o mundo natural (1988), e Simon Schama, em Paisagem e memória (1996), discutem, nas ocorrências na virada do século XVIII para o XIX, as sutilezas e as ambiguidades da apreciação dos homens ora pela natureza domesticada ora pela natureza selvagem. De acordo com esses autores, a concepção de natureza decorre de uma construção mental e social, cuja fundação se dá pela cultura e pela história. Simon Schama volta as duas arcádias que se originaram naquele tempo e constituem a matéria-prima do que fomenta até hoje as visões dicotômicas do mundo natural. Sempre houve dois tipos de arcádia, diz ele: tumultuada e tranquila; sombria e luminosa; um lugar de ócio bucólico e um lugar de pânico primitivo. Mesmo que, levando-se em conta tanto as condições da urbanidade e da historicidade, as visões do que é a natureza, por mais diversas, são construções mentais, cujas significações vão sendo moldadas de acordo com interesses e necessidades, quer materialistas, quer espirituais ${ }^{1}$.

Segundo Robert Lenoble, desde o marco histórico da "Suma teológica" do século XVIII, início da luta entre o mecanicismo-racionalismo e o vitalismo, o conceito Natureza carrega vários sentidos (Lenoble, 1990, p. 284). Para o autor, a natureza toma sentidos completamente diferentes de acordo com as épocas e os homens. Distinguiríamos desde os tempos modernos, afirma Lenoble, a natureza observada do biólogo da natureza sonhada do poeta, diferentemente do que acontecia na Idade Média, quando as duas eram, então, a única e mesma coisa, porque a própria realidade física era concebida como um símbolo do mundo religioso e moral (Lenoble, 1990, p. 217).

1 As reflexões deste tópico estão mais aprofundadas e bem mais detalhadas na tese da autora sobre o imaginário rural e leitores urbanos (SILVA, G., 2009). 
A ideia mesma da oposição entre Homem e Natureza pode ser considerada uma construção sociocultural, pois, embora estejamos habituados a situar natureza e percepção humana em dois campos distintos, elas se mostram cada vez mais inseparáveis. Philippe Descola postula que a clivagem fundamental estabelecida pelo Ocidente entre natureza e cultura pode nada significar para outros povos que veem as plantas e os animais também como sujeitos sociais e não como objetos. Diz que é preciso admitir que nossa concepção sobre a natureza, herdada do século XVII, não é mais operante.

Graças ao crescimento das preocupações ecológicas, admitimos atualmente que plantas, animais, genes, desertos, correntes marinhas ou a química da atmosfera não existem dentro de um universo à parte, justaposto ao nosso. Isso não quer dizer que eles não possam ser assunto de um conhecimento especializado. Isso significa somente que a divisão entre "natureza" e "sociedade", fundamento da cosmologia ocidental, não percebe de forma adequada a organização do mundo (Descola in Passis-Pasternak, 2001, p. 114).

Muitos autores identificam no movimento ecológico a mais recente tradução do desejo humano de retorno à natureza. E mais, percebem nele também a manifestação da vontade do homem de ressacralizar o mundo natural e, desse modo, conectar-se novamente à sacralidade divina. O próprio mito do paraíso nada mais é que o relato da perda da dimensão sagrada; e a busca incansável por esse Éden ocorre, segundo Heinberg, no sentido de alcançar um estado em que todos os desejos e motivos humanos sejam incluídos dentro de um propósito criativo maior, "porque o desejo avassalador de todos os indivíduos é que o acordo consumado da Natureza e do Cosmos seja alimentado e mantido" (Heinberg, 1991, p. 297). Sheldrake (1997) também destaca os vestígios do sagrado na visão ecológica do mundo. Acredita que o movimento verde estimula o relacionamento espiritual com a natureza. Comentando sobre a qualidade transcendental de muitos parques nacionais, o autor diz que para muitos visitantes esses parques são mais do que áreas de recreação, são templos ou santuários naturais.

Mas essa reviravolta filosófica e antropológica está apenas dando seus primeiros sinais rumo à visão biocêntrica do mundo. Na prática histórica, desde que a humanidade se posicionou como observadora distanciada e interventora do mundo natural, o ser humano tem dificuldade em se deslocar de sua visão antropocêntrica. E seguimos em paroxismos. A mesma natureza tomada pela ciência como sistema inanimado e mecânico, a ser explorado para o progresso humano, continua sendo percebida pela nossa intuição como Mãe Natureza, tanto a benevolente e sábia como a ameaçadora e misteriosa. Lenoble reafirma 
que a Natureza surgiu no pensamento dos homens como construção, sob regência da reflexão e não arbitrariamente. E acusa a artificialidade da separação da ideia de Natureza em três campos: científico, moral e estético. Ele aponta a interferência que a modificação do conceito em um dos campos pode exercer nos outros e busca a âncora da história: o "conceito de Natureza só na história toma sentido: exprime menos uma realidade passiva apercebida que uma atitude do homem perante as coisas" (Lenoble, 1990, p. 200). Nesta mesma perspectiva, Schama, ao fazer uma arqueologia da paisagem, afirma que

paisagem é cultura antes de ser natureza, um constructo da imaginação projetado sobre mata, água, rocha [...] cabe também reconhecer que, quando uma determinada ideia de paisagem, um mito, uma visão, se forma num lugar concreto, ela mistura categorias, torna as metáforas mais reais que seus referentes, torna-se de fato parte do cenário (Schama, 1996, p. 70).

O autor assume posição necessariamente histórica e por isso mesmo, como ele diz, menos universal, já que "nem todas as culturas abraçam natureza e paisagem com igual ardor, e as que abraçam conhecem fases de maior ou menor entusiasmo" (Schama, 1996, p. 25). Mesmo levando em conta as variações, reconhece que "os mitos e lembranças da paisagem partilham duas características comuns: sua surpreendente permanência ao longo dos séculos e sua capacidade de moldar instituições com as quais ainda convivemos"(Schama, p. 25-26). Este é, na verdade, o grande desafio: compreender a diversidade das ideias, sensibilidades e atitudes com relação à natureza - elaboradas pelas diferenças de classe ou modificadas pelas condições histórico-culturais - e o estofo comum que permanece, como herança, por detrás de tais diferenças.

Ao perseguir os rastros históricos da "conquista ou preservação?" da natureza, Keith Thomas (1988) encontra fundamentos religiosos para explicar a defesa recente da proteção do mundo natural, na qual vamos encontrar sinais daquela persistência de que falava Raymond Williams (1989) e das obsessões identificadas por Simon Schama (1996). Ele argumenta que, antes de ganhar fundamento científico, a ideia atual do equilíbrio da natureza teve base teológica e que foi a crença na perfeição do desígnio divino que precedeu e sustentou o conceito de cadeia ecológica (Thomas, 1988, p. 329).

Podemos dizer o mesmo sobre atitudes ecológicas dos últimos 30 anos, tanto as mais radicais, que não suportam a ideia da presença de moradores dentro dessas catedrais, quanto as outras que lidam com "construção" de parques urbanos, santuários erguidos justamente para serem frequentados pelos homens. Independentemente da diferença de propósitos - uns mais animistas e amantes da vida agreste, e outros mais humanistas, antropocêntricos e defensores da vida domesticada - essas atitudes dos ecologistas revelam 
resquícios da presença do sagrado na relação homem-natureza. E podem, num caminho inverso, realimentar este sagrado. É exatamente o que sugere Rupert Sheldrake (1997, p. 184): no decorrer das duas últimas décadas, com a ascensão do movimento verde e a crescente consciência da crise ecológica, membros de diferentes tradições religiosas têm se empenhado na redescoberta do seu relacionamento espiritual com o mundo vivo. Não há como discordar do autor quando afirma que moradores urbanos esquecem com facilidade as fontes naturais de sua subsistência e, por isso, os movimentos verdes, ecológicos, cumprem importante papel de lembrar-lhes da finitude dos recursos, da destruição provocada pelas demandas do homem e da problemática da poluição e dos resíduos gerados. Quanto mais a qualidade do urbano se deteriora, mais os habitantes da metrópole trazem-na para a pauta do dia.

Em trabalho de 1994, Antonio Carlos Sant'Ana Diegues discute a questão ambiental a partir do que chama de "mito moderno da natureza intocada". O debate entre ambientalistas, como se pode verificar, se dá justamente pela separação entre preservacionistas e conservacionistas. A primeira corrente propõe o isolamento das áreas naturais, onde o homem pode entrar apenas para apreciação estética e espiritual da vida selvagem. O ponto de vista é o urbano, de quem olha de fora - esse modelo de áreas protegidas, criado nos Estados Unidos, tem sido muito adotado pelos países de Terceiro Mundo. O segundo movimento, dos conservacionistas, pressupõe o uso criterioso e racional dos recursos naturais - modelo que admite a presença de populações tradicionais, de pescadores, camponeses e indígenas, junto ao ambiente natural conservado. Vê-se a partir de dentro do lugar. Essas duas posições nada mais são que novas versões daquelas velhas e dicotômicas concepções da relação homem-natureza. Em diferentes imagens. Árcades pré-selênicos ou virgilianos? Arcádia primitiva ou habitável? Terra inculta ou cultivada? Civilidade e harmonia ou integridade e indisciplina? Animistas ou humanistas? Vitalistas ou culturalistas? Natureza ou homem?

Para investigar as imagens sobre a natureza nos jornais Folha de $S$. Paulo e $O$ Estado de S. Paulo, complexificamos essa coleção de imagens, não de forma dicotômica ou estática, mas como uma constelação, em movimento e rearranjos, conforme propõe Gilbert Durand (1997). No contexto, questões relevantes no repertório das transformações e desafios na virada do século XX para o XXI, como cuidados com o meio ambiente, anseios por qualidade de vida, conquistas mercadológicas, avanços e riscos das novas técnicas e produtos da biotecnologia, discussão sobre bioética e o aguçamento pendular entre fascínio e temor da humanidade diante das descobertas das ciências. Todas elas presentes no nosso cotidiano. E sabendo que cotidiano e jornalismo 
vivem numa relação simbiótica, considerou-se aqui a validade científica de se averiguar na cultura midiática, a partir de uma 'observação sensível', a agência do relato jornalístico na reprodução, atualização e potencialização de imagens da natureza, a partir de um corpus de material jornalístico da imprensa escrita diária, localizada no período das últimas três décadas, para a observação de diferentes imagens de natureza.

\section{Percurso metodológico}

Pela perspectiva epistemológica da metodologia, adotou-se a combinação adaptada de dois métodos de Gilbert Durand, a mitocrítica e a mitanálise (Durand, 1983, 1984, 1998), próprios para serem aplicados a relatos, quer literários ou sociológicos, e, como aqui proposto, a textos jornalísticos. A mitocrítica se faz sobre uma obra literária ou um autor (textos) e a mitanálise, mais abrangente, se faz em terreno social amplo (sociedade). Os estudos de seguidores do pensamento de Durand levaram a uma ampliação da mitocrítica para a mitanálise ${ }^{2}$.

No caso do jornalismo, podemos incluí-lo como um dos bens desse inventário antropológico (Durand citado por Pitta, 2005, p. 102), pensado como uma tópica sociocultural da expressão do imaginário social, com uma gramática específica e com uma dinâmica que perpassa concomitantemente texto e sociedade, num continuum. Isso porque estamos tratando de

matérias jornalísticas, atravessadas por discursos diversos, que testemunham, criam e repercutem o imaginário de uma época não só pela expressão de tendências estéticas e/ou das impressões de um autor/jornalista em especial, como pressupõe a mitocrítica, mas também por meio do registro dos fatos, dos acontecimentos, dos eventos e da vida cotidiana, da comunhão social de momentos, experiências e valores, da documentação das disputas concretas e simbólicas que enredam a teia da história e remetem, portanto, a um contexto histórico amplo, compartilhado pela sociedade como um todo e exterior aos textos (Maia, 2011, p. 27).

2 Este modo de trazer no artigo o pensamento de Gilbert Durand para pensar imagens de natureza, mais metodológico, é diferente da maneira como a pesquisadora francesa Hélène Houdayer discutiu Durand e natureza em sua conferência num evento na PUCRS, Porto Alegre, no ano de 2015 (texto foi publicado na Revista Famecos, em 2017). Houdayer explica em Durand a engrenagem dos três eixos dirigentes das imagens (postural, copulativo e digestivo) e dos dois regimes de significações (diurno e noturno) para problematizar diretamente a negociação sociedade-natureza. Também eu, no livro 0 sonho da casa no campo: jornalismo e imaginário de leitores urbanos, trabalhei com textos de Durand de modo similar ao da pesquisadora francesa. No caso deste estudo aqui, busquei em Durand sua proposição metodológica de mitocrítica e mitanálise para pensar, no âmbito da cobertura jornalística sobre natureza, o trânsito entre textos específicos e discursos sociais alargados. 
Por isso a sugestão da combinação adaptada de mitocrítica e mitanálise se dá pelo entendimento de que o texto jornalístico transita entre sua própria linguagem codificada e o 'ouvir dizer que' no qual se fundamenta a produção jornalística, por meio das rotineiras entrevistas com suas fontes, e pelo qual se dá repercussão das notícias entre os receptores. Importante considerar o relato jornalístico (de qualquer matéria jornalística: hardnews, softnews, opinativa, sensacionalista etc.) como lugar de expressão (clara ou obscura, latente ou facilmente visível) do imaginário social compartilhado por todos os sujeitos envolvidos no universo das notícias, sejam repórteres, leitores/receptores, fontes, publicitários, proprietários de veículos noticiosos, editores, anunciantes. Insisto que ambos, produtores e receptores de notícias, compartilham imaginários, e por isso é que podemos estudar esse mundo imaginal tanto no texto - como está sendo feito aqui neste estudo - como também na observação e coleta junto aos jornalistas, e na recepção, junto a leitores, ouvintes, telespectadores e navegadores virtuais.

E pela perspectiva operacional da metodologia, tomaram-se como objeto empírico as edições impressas de dois jornais diários de circulação nacional, Folha de S. Paulo (período de 1995 a 2012) e O Estado de S. Paulo (período de 1995 a 2012). No total, 915 unidades noticiosas foram trabalhadas qualitativa e quantitativamente, seguindo esses passos metodológicos:

- fiz visitas às sedes dos dois jornais, para consulta em seus bancos de dados $^{3}$;

- para viabilizar o alargamento do corpus para edições de diversos anos, inclusive de décadas diferentes (anos 90, 00 e 10), decidi por buscas pela palavra natureza apenas nos títulos dos materiais (descartados os classificados, cartas do leitor, publicidades);

- não houve distinção de editorias ou seções, nem entre textos informativos e opinativos, uma vez que interessavam à pesquisa as imagens de natureza presentes nas mais diversas situações noticiosas, fosse em matéria de economia ou turismo, notícia curta, artigo assinado ou editorial;

- $\quad$ por questões técnicas, o período demarcado para o corpus se deveu à viabilidade de acessar os arquivos eletrônicos das matérias/textos ${ }^{4}$;

3 Foi realizado, antes, um exercício-piloto junto ao banco de dados do jornal Folha de S. Paulo, no qual se verificou no total das edições do ano de 2011 a ocorrência da palavra 'natureza' em 1.200 textos; se considerada apenas a presença do termo 'natureza' nos títulos desses materiais, havia o registro em 39 vezes e também outros 29 títulos com a palavra 'natural'.

4 Embora a Folha de S. Paulo tivesse em formato eletrônico até aquele momento as edições desde 1995, O Estado de S. Paulo havia começado no ano de 1996 - para viabilizar a junção dos dados totais dos dois veículos, foi criado o ano artificial de '1995' para o Estadão a partir da média de dois anos 
- em material bruto, coletado pela busca do termo'natureza' nos títulos dos textos dos dois jornais, foram obtidas 1.440 unidades informativas. Descartamos os materiais repetidos, os títulos de cadernos (títulos de capa, vazios de conteúdo) e os materiais em que o termo natureza não estava vinculado ao mundo natural, mas sim à natureza humana (questões mais filosóficas sobre a existência do ser humano), à natureza da arte e à natureza das coisas (da guerra, do esporte, do samba, da arquitetura, da moda, natureza de signos do horóscopo etc.). Ao final, o corpus se consolidou em 411 unidades informativas da Folha e 504 do Estadão, num total de 915 unidades analisadas.

As concepções de natureza foram organizadas na forma de vínculos. A consolidação das noções-vínculo exigiu muitas idas e vindas ao objeto empírico ${ }^{5}$, de modo a se chegar a uma percepção da dominância de uma imagem de natureza específica em matérias em que havia mais de uma imagem de natureza. Isso revela quão polifônica pode ser uma mesma matéria, sobretudo quando envolve não somente a intenção de quem escreve ou de quem titula, mas também a interpretação subjetiva de quem a lê, como ocorre no caso dos variados pesquisadores que a analisam.

\section{As imagens de natureza em Folha de S. Paulo e O Estado de S. Paulo}

Os conjuntos de imagens identificados e sistematizados a partir do manuseio dos materiais empíricos foram os seguintes: (1) Cultuada; (2) Admirada; (3) Preservada; (4) Simbiótica; (5) Ameaçada; (6) Domesticada; (7) Punidora e (8) Imprevisível. Essa ordem de conjuntos se deve à intencionalidade de partir da imagem de natureza mais intocada, mais venerada, passando pela ideia de preservação, pela do convívio harmonioso com o mundo natural, depois se dando conta das ameaças, em seguida a ideia de dominação e domesticação a natureza, para se chegar ao entendimento de que a natureza responde às violências humanas e reage de modo vingativo ou punidor, e, por fim, a ideia de que não dominamos a natureza, dona de grande força e imprevisibilidade, como nos casos das catástrofes naturais que independem da ação da humanidade.

próximos (1996 e 1997), de modo a construir equilibradamente gráficos com dados trienais. A opção pela leitura em triênios para elaborar os gráficos se deveu ao grande volume de unidades analisadas que, se dispostas anualmente, dificultavam a visibilidade dos dados nos gráficos, como se poluído por tantas linhas e pontos.

5 Importante registrar que participaram da manipulação dos materiais empíricos os graduandos Luisa Tavares e Gabriel Shiozawa Coelho (bolsistas de Iniciação Científica), a mestranda Danielle Sibonis (bolsista Capes) e Jeana Santos, em estágio pós-doutoral (bolsista Capes). 


\section{Cultuada}

Mais do que bela, a natureza é majestosa e envolta em mistério, sendo considerada sagrada. A relação com a humanidade não se dá em pé de igualdade: o homem aparece como pequeno, submetido às suas regras e silenciado perante sua grandiosidade. A superioridade é tão grande que ela deve permanecer intocada, os humanos devem apenas contemplá-la. Os ambientes são extraordinários e qualquer interferência na natureza prejudicaria a harmonia e a beleza presentes.

\section{Admirada}

A natureza é bela e deve ser admirada. O homem pode conviver, sem interferir ou danificar, aproveitar a dádiva que os ambientes proporcionam. A natureza é também acolhedora, um lugar de retorno ao qual os homens podem recorrer quando buscam ar puro, terra fértil, água cristalina, além de uma flora e fauna exuberantes. A natureza, em seus qualitativos, acaba sendo de certa forma instrumentalizada: sua calma, beleza e sabores adquirem valor e diversos serviços são oferecidos, sobretudo de ecoturismo e gastronomia. A natureza pode assumir características e virtudes humanas como a bondade, sabedoria, paciência.

\section{Preservada}

A preservação da natureza aparece segundo duas perspectivas: em favor de uma harmonia entre homem e natureza e para a proteção dos recursos naturais que mantêm nossa espécie viva. Embora a humanidade seja percebida como separada da natureza, há o reconhecimento de que é preciso criar ações que permitam um meio termo entre o que os humanos precisam e querem, aliando desenvolvimento com a preservação dos ambientes naturais. As atitudes humanas buscam um equilíbrio sustentável que não exceda os limites da natureza nem prejudique as próximas gerações no suprimento de suas necessidades, propondo a criação de produtos biodegradáveis, reciclagem e produção de energias renováveis. A sustentabilidade é um valor.

\section{Simbiótica}

Há o reconhecimento de que o homem, sua história e sua cultura fazem parte da natureza. Há uma conexão que envolve o respeito e o reconhecimento das diversidades, buscando o equilíbrio e a harmonia com as demais formas de vida. A natureza é vivenciada como fonte de subsistência e de conhecimento. 0 homem se adapta ao meio: o mundo natural não é visto de fora, mas através de um sujeito que faz parte dele. São exemplos de atitudes simbióticas: respeitar o 
ritmo da natureza, favorecer métodos tradicionais de cultivo e criação e o bemestar dos animais.

\section{Ameaçada}

O homem, incessantemente, destrói a natureza, que é incapaz de se defender por conta própria. A natureza é martirizada, tem-se um cenário de pilhagem ecológica em que a humanidade, na marcha rumo ao progresso, armada pelo conhecimento científico, é indiferente aos efeitos de suas atitudes e ignora sua vítima. Existe também uma relação paradoxal: em oposição à destruição causada pela ação humana, o homem se coloca como vigilante e protetor da natureza, que é uma vítima agonizante, precisando de ajuda.

\section{Domesticada}

O meio aparece como subjugado ao homem, sendo domesticado para atender às suas demandas. A natureza é vista como desprovida de valor próprio, existindo somente para servir, sendo explorada na forma de "recursos naturais". A natureza é dominada, ordenada, classificada, produzida artificialmente, a partir de um pensamento ligado ao racionalismo e cientificismo, cujo objetivo é o domínio do conhecimento. Os danos ambientais são justificados pela missão civilizadora, pela necessidade do"fazer ciência"e do progresso/desenvolvimento que tenta retirar dela todos os perigos e ameaças, dando poder, liberdade e conforto para a vida em sociedade. A própria sociedade opera de maneira coercitiva, lutando para sobrepor o racional ao instintivo. Assim, há uma ruptura entre homem e natureza, a partir da visão utilitarista segundo a qual o mundo natural é um objeto e o humano o sujeito que usufrui dele.

\section{Punidora}

Quando destruída pelo homem, a natureza revida. Ao desrespeitar o equilíbrio e o balanço natural, os humanos são punidos severamente por uma natureza que é combativa, violenta, que intencionalmente causa desastres naturais e pragas. A natureza emerge como uma criatura complexa e impetuosa, que exige ser respeitada. Há uma relação de causa e consequência: a ação destrutiva do homem seguida pela punição colérica da natureza. Ela também assume características humanas, como a fúria e a vingança.

\section{Imprevisível}

A natureza age apesar da humanidade, de forma aleatória e com causas desconhecidas. É percebida como inexorável, indomável, temida por sua força e perigo eminentes. É o caso dos desastres naturais, incontroláveis e marcados 
pela dificuldade ou impossibilidade de previsão, do ataque de pragas que consomem lavouras e de predadores, feras selvagens que agem de forma inesperada. O mundo natural é imprevisível. Quando o ambiente age de forma a quebrar a expectativa que se tinha dele, o homem reconhece sua aleatoriedade e os perigos que enfrenta em um meio que não consegue controlar.

Em termos quantitativos, encontramos os seguintes resultados, ano a ano nos dois veículos analisados (Figura 1):

Figura 1: Conjuntos de imagens de natureza ano a ano em Folha de S. Paulo e O Estado de S. Paulo (1995 - 2012)

\begin{tabular}{|c|c|c|c|c|c|c|c|c|c|c|c|c|c|c|c|c|c|c|c|}
\hline \multicolumn{20}{|c|}{ FREQUÊNCIA Imagens de natureza em Folha de S.Paulo e O Estado de S.Paulo (1995-2012) } \\
\hline IMAGENS & 1995 & 1996 & 1997 & 1998 & 1999 & 2000 & 2001 & 2002 & 2003 & 2004 & 2005 & 2006 & 2007 & 2008 & 2009 & 2010 & 2011 & 2012 & Total \\
\hline Cultuada & 7 & $1 \mid$ & 3 & 2 & 6 & 1 & 5 & 5 & 3 & 1 & \begin{tabular}{|r|}
2 \\
\end{tabular} & 5 & 2 & 3 & 6 & 0 & 2 & 1 & \\
\hline Admirada & 22 & 18 & 30 & 29 & 26 & 29 & 36 & 28 & 27 & 26 & 23 & 17 & 12 & 15 & 12 & 19 & 24 & 20 & 4 \\
\hline Preservada & 3 & 2 & 5 & 3 & 8 & 8 & 15 & 9 & 11 & 5 & 14 & 13 & 7 & 7 & 6 & 8 & 7 & 3 & 1 \\
\hline Simbiótica & 0 & 0 & 2 & 3 & 0 & 4 & 2 & 2 & 2 & 1 & 0 & 1 & 1 & 2 & 1 & 1 & 1 & 0 & \\
\hline Ameaçada & 4 & 2 & 5 & 3 & 13 & 17 & 12 & $\overline{7}$ & 3 & 1 & 5 & 6 & 5 & 4 & 4 & 5 & 5 & 4 & $\overline{1}$ \\
\hline Domesticada & 2 & 4 & 7 & 5 & 0 & 5 & 6 & 6 & 5 & 7 & 4 & 4 & 10 & 7 & 5 & 6 & 5 & 4 & \\
\hline Punidora & 2 & 2 & 0 & 2 & 0 & 1 & 1 & 1 & 0 & 4 & 3 & 0 & 1 & 1. & 1 & 2 & 0 & 3 & \\
\hline Imprevisível & 1 & 3 & 3 & 3 & 0 & 7 & 4 & 6 & 4 & 1 & 5 & 2 & 3 & 4 & 6 & 11 & 6 & 1 & \\
\hline TOTAL & 40 & 32 & 55 & 50 & 53 & 72 & 81 & 64 & 55 & 46 & 56 & 48 & 41 & 43 & 41 & 52 & 50 & 36 & \\
\hline
\end{tabular}

Somando os totais dos anos e calculando suas porcentagens, temos abaixo (Figura 2) esses dados de modo mais visível na ordem decrescente das frequências:

Figura 2: Conjuntos de imagens de natureza em Folha de S. Paulo e O Estado de S. Paulo

$(1995$ - 2012)

\begin{tabular}{|l|r|c|}
\hline \multicolumn{3}{|l}{ Imagens de natureza em FSP e OESP } \\
\hline \multicolumn{1}{|c|}{ IMAGENS } & FREQUÊNCIA & $\%$ \\
\hline Admirada & 413 & 45 \\
\hline Preservada & 134 & 15 \\
\hline Ameaçada & 105 & 11 \\
\hline Domesticada & 92 & 10 \\
\hline Imprevisível & 70 & 8 \\
\hline Cultuada & 55 & 6 \\
\hline Punidora & 24 & 3 \\
\hline Simbiótica & 23 & 3 \\
\hline TOTAL & $\mathbf{9 1 5}$ & $\mathbf{1 0 0 , 0}$
\end{tabular}

Com base na frequência, observamos a predominância da imagem admirada sobre as demais (representando $45 \%$ do total), uma admiração da natureza entendida como "acolhedora, um lugar de retorno ao qual os homens podem recorrer quando buscam ar puro, terra fértil, água cristalina, além de uma flora e fauna exuberantes. A natureza, em seus qualitativos, acaba sendo de certa forma instrumentalizada: sua calma, beleza e sabores adquirem valor e diversos serviços são oferecidos, sobretudo de ecoturismo e gastronomia". 
Por uma leitura mais qualitativa, percebemos que grande parte dos materiais deste conjunto de imagens era da editoria de turismo, o que, na maioria das vezes, pressupõe que a natureza seja retratada de forma agradável. Mas por que, na busca realizada, acabou-se por encontrar grande maioria de matérias de turismo? Por um lado, a editoria pode ser, realmente, a que mais trata do assunto trabalhado. Por outro, pode ser que, enquanto o turismo foca a natureza como um algo mais idealizado e por isso dá o destaque no título, outras matérias tratam do assunto indiretamente, não elegendo o termo para titular a peça. Isso porque, para relembrar, as notícias selecionadas para compor o corpus desta pesquisa responderam ao critério de seleção da presença da palavra natureza no título. É provável que, no texto de uma reportagem de outras editorias, apareçam imagens de natureza. Mas o fato de termos limitado a busca às matérias que continham a palavra natureza no título limitou a possibilidade de encontrar outras matérias com outras tantas menções à natureza. Por exemplo, notícias cujas pautas tratassem de atitudes simbióticas, ou seja, das formas mais equilibradas de relação do homem com a natureza, sem ter usado esta palavra no título não foram selecionadas para a análise. Ou então, em acontecimentos jornalísticos que tratassem de situações de riscos ou catástrofes naturais, os materiais noticiosos tenham recebido títulos mais sensacionalistas, nos quais a palavra natureza não tenha sido utilizada e, por isso, tenham ficado invisíveis na ação de demarcação do corpus.

Outra percepção analítica diz respeito à segunda imagem com a segunda maior frequência, a preservada (15\%) - conforme a explicitação desta categoria, "embora a humanidade seja percebida como separada da natureza, há o reconhecimento de que é preciso criar ações que permitam um meio termo entre o que os humanos precisam e querem, aliando desenvolvimento com a preservação dos ambientes naturais. As atitudes humanas buscam um equilíbrio sustentável que não exceda os limites da natureza nem prejudique as próximas gerações no suprimento de suas necessidades, propondo a criação de produtos biodegradáveis, reciclagem e produção de energias renováveis. A sustentabilidade é um valor". Embora com diferença marcante entre os dois jornais em separado, aqui, quando juntos, os materiais revelam o lugar de destaque que a ideia de necessidade de preservação da natureza tem atualmente no nosso cotidiano.

Na sequência, quase empatadas, aparecem as imagens ameaçada (11\%) e domesticada (10\%). Analisando primeiramente a imagem ameaçada, temos que, vindo logo após o conjunto de imagens preservada, podemos dizer que a dupla preservada-ameaçada costuma andar de par (até mesmo em cada jornal elas ocorrem com a mesma proximidade). Em muitas matérias essas duas 
imagens aparecem, com maior ou menor ênfase, correlacionadas. Foi bastante comum, inclusive, encontrar referências às duas imagens na mesma matéria, por conta desse aspecto paradoxal que as une. Ou seja, na mesma medida em que o imaginário coletivo entende a natureza como ameaçada, ele mobiliza esforços e percebe a necessidade de preservá-la. Assim, o patamar alto de admirada seguido daqueles vinculados aos de preservação ou de risco em busca de ações preservacionistas revela a primazia dos qualitativos da natureza frente aos demais conjuntos de imagem que povoam nosso imaginário contemporâneo. Com relação à domesticada, podemos entender que, apesar de perceber com admiração a natureza e estar atenta a sua preservação e às ameaças que sofre, a sociedade mantém sua visão pragmática dos bens naturais, como origem de recursos necessários para desenvolvimento das sociedades. Nesse material jornalístico, encontramos claramente a ideia explicitada na definição que fizemos desta categoria/conjunto de imagens; a ideia de que "a natureza é dominada, ordenada, classificada, produzida artificialmente, a partir de um pensamento ligado ao racionalismo e cientificismo, cujo objetivo é o domínio do conhecimento. Os danos ambientais são justificados pela missão civilizadora, pela necessidade do 'fazer ciência' e do progresso/desenvolvimento que tenta retirar dela todos os perigos, dando poder, liberdade e conforto para a vida em sociedade. A própria sociedade opera de maneira coercitiva, lutando para sobrepor o racional ao instintivo. Assim, há uma ruptura entre homem e natureza, a partir da visão utilitarista segundo a qual o mundo natural é um objeto e o humano o sujeito que usufrui dele".

A ocorrência da imagem de natureza imprevisível (8\%), logo após a da domesticada (10\%), pode demonstrar a limitação desse poder de dominar e controlar o mundo natural, uma vez que "o ambiente age de forma a quebrar a expectativa que se tinha dele" e o homem "reconhece sua aleatoriedade e os perigos que enfrenta em um meio que não consegue controlar".

Com relação às imagens de menor ocorrência, temos cultuada (6\%) e por último, empatadas, as noções-vínculos simbiótica (3\%) e punidora (3\%). Interessante observar que essas três são as de maior carga mítica e antropológica: a cultuada, percebida como "mais do que bela, a natureza é majestosa e envolta em mistério, sendo considerada sagrada. A relação com a humanidade não se dá em pé de igualdade: o homem aparece como pequeno, submetido as suas regras e silenciado perante sua grandiosidade. A superioridade é tão grande que ela deve permanecer intocada, os humanos devem apenas contemplála"; a simbiótica, com "o reconhecimento de que o homem, sua história e sua cultura fazem parte da natureza" e com a "conexão que envolve o respeito e o reconhecimento das diversidades, buscando o equilíbrio e a harmonia com as 
demais formas de vida"; e a punidora, pelo entendimento de que ao "desrespeitar o equilíbrio e o balanço natural, os humanos são punidos severamente por uma natureza que é combativa, violenta, que intencionalmente causa desastres naturais e pragas" e de que "há uma relação de causa e consequência: a ação destrutiva do homem seguida pela punição colérica da natureza", incorporando "características humanas, como a fúria e a vingança".

Observando os resultados das frequências com que as imagens aparecem nos materiais jornalísticos analisados, podemos concluir que, de modo geral, eles nos mostram a percepção da natureza como um outro, algo externo a nós, humanos; num quadro de afastamento, como se o homem não fizesse parte da natureza, seja a natureza tomada comoum lugarprazeroso (admirada), explorável (domesticada), em risco (preservada e ameaçada) ou perigosa (imprevisível). A natureza é admirada, domesticada, ameaçada, preservada, cultuada, punidora e imprevisível como um outro que não é "nós". O fato de o imprevisível apresentar também uma porcentagem considerável pode querer nos dizer que o homem se mostra perplexo e por vezes assustado, pois, apesar de seus grandes esforços, grande parte da natureza ainda é indomável e assustadora. Também a ocorrência da noção-vínculo simbiótica ser tão baixa reforça a ideia de que a imagem mais forte no imaginário coletivo é a de uma natureza na qual o homem não está incluído, da qual não faz parte, somente mora nela. A referência quanto à sacralidade conferida à natureza é ínfima no corpus de pesquisa, como visto nos dados sobre natureza cultuada. A não interferência na harmonia natural parece muito distante de nós, inseridos que estamos na perspectiva hegemônica de desenvolvimento econômico e tecnológico.

Para além das frequências, foi feita ainda uma análise dos movimentos temporais dessas imagens no decorrer dos 18 anos estudados, pela qual podemos perceber melhor o aumento ou a diminuição de tais imagens no decorrer do período analisado. As variações das imagens de natureza entre 1995 e 2012 revelaram que a imagem admirada está em patamar consideravelmente superior às demais (em 413 das 915 unidades - por força da editoria de turismo como dito antes), com um pico no triênio 2001-2003, queda acentuada até o triênio $2007-2009$ e, finalmente, com uma subida significativa no último triênio 2010-2012. Aqui seria necessária outra investigação para levantamento dos fatos ocorridos no ambiente/sociedade para compreensão mais profunda desse movimento temporal.

Outra questão relevante parece ser o crescimento do conjunto de imagens do conjunto imprevisível no último triênio, provavelmente em função do aumento de catástrofes ambientais - dados comparativos a serem levantados podem confirmar essa inferência. Preocupante a queda constante de 
materiais jornalísticos em que a natureza preservada tem destaque na imprensa analisada. Se vinha em patamares mais altos, no último triênio a noção-vínculo preservação voltou ao nível dos registros do triênio inicial, ou seja, em 20102012 cai para o mesmo patamar de 1995-1997. Na correlação temporal da cobertura jornalística sobre natureza preservada ou que pede preservação, tem-se a interferência direta de ocorrências de ligadas a catástrofes e crimes ambientais, como supostamente pode ser o caso do conjunto ameaçada, que teve um pico no triênio 1998-2000 - também aqui seria bem-vinda uma investigação de conteúdo/temática para comprovar tal percepção. Por fim, entre os destaques dessa análise temporal, podemos inferir que a percepção da natureza como igual (simbiótica) e como superior ao homem (cultuada), além de não ser recorrente na sociedade, enfraqueceu-se no período analisado.

Não há como afirmar que tais movimentos, no decorrer dos 18 anos analisados, tratem de grandes tendências. Talvez sejam fenômenos explicáveis por fatores externos à produção jornalística (por exemplo, diminuição ou aumento do número de desastres naturais, divulgação de estudos sobre o desmatamento etc.). O que se pode pensar de imediato é na própria fotografia que nos revelam os resultados de cada imagem em relação umas às outras e, em alguns momentos, movimentos particulares de cada uma no passar dos anos.

\section{Notas finais}

Neste estudo, o que se buscou, de modo específico, foi identificar e explicitar imagens de natureza na imprensa escrita brasileira, no intervalo de virada do século XX para o XXI, como bens de uma parcela específica do inventário do imaginário coletivo e social - sem perder de vista a perspectiva histórica, uma vez que a temporalidade é constitutiva do jornalismo. E sem ignorar também que os profissionais da imprensa adotam concepções de mundo de parte do seu público justamente por estarem inseridos na mesma sociedade dos que consomem as notícias.

E, como objetivo mais amplo, procurou-se compreender a ação da imprensa nesse processo de produção, reprodução, criação e circulação de imaginários. O jornalismo, tomado como uma "fonte que alimenta com imaginários o cotidiano contemporâneo e, ao mesmo tempo, de imaginários sociais alimenta a si mesmo" (Silva, 2010, p. 250), foi trabalhado aqui como um lugar de expressão do imaginário coletivo, um locus fecundo de observação desses vestígios imaginais, uma vez que as notícias trazem toda a diversidade do mundo, da política e da economia à arte e ao entretenimento, incluindo as próprias ocorrências ordinárias, do dia a dia. 
No que diz respeito diretamente às relações do jornalismo com as questões da natureza e do mundo natural, eu diria que se trata de grande obrigação acadêmica, a de participar de problema tão central na sociedade contemporânea ${ }^{6}$. Como bem explicitou a pesquisadora francesa Hélène Houdayer, nos dias de hoje nós somos obrigados a trabalhar com uma noção de ambiente olhando "nossos hábitos de consumo, a maneira com que nos tratamos e percebemos os riscos (avalanches, inundações, climas, genéricos etc.), o uso da técnica", e isso, consequentemente, exige de nós uma nova postura de pesquisa, "pois não se trata unicamente de descrever as relações com a natureza, mas inventar (ou reinventar) novos tipos de negociação nas relações sociedade-natureza, novas práticas a partir das técnicas e representações do meio natural" (Houdayer, 2017).

Para concluir, a umas das incontáveis problemáticas de Kate Soper, em seu livro Whats is nature?:

\begin{abstract}
A natureza também carrega uma carga simbólica imensamente complexa e contraditória; é objeto de ideologias muito contrárias; e vem sendo representada em uma enorme variedade de maneiras diferentes. Em tempos recentes, passou a ocupar um lugar central na agenda política como resultado da crise ecológica, onde os números são um conceito geral através do qual somos convidados a repensar nosso uso atual de recursos, nossas relações com outras formas da vida, nosso lugar aí dentro e nossas responsabilidades em relação ao ecossistema (Soper, 2000, p. 2, tradução nossa ${ }^{7}$ ).
\end{abstract}

O desafio em pensar respostas se dá no enfrentamento da ruptura primordial entre natureza e cultura, entre homem e mundo natural. Nossa

6 Em sua dissertação, Flávia Dourado Maia, por mim orientada, estudou nas edições da revista Globo Rural de 1985 a 2010 as transformações pelas quais as imagens e o imaginário de natureza passaram durante essas décadas e encontrou imagens muito diversas entre o imaginário antropocêntrico e 0 biocêntrico. A coexistência de imagens tão contrastantes colocou em evidência a permeabilidade da simbologia mítica às conjunturas históricas ou, em outras palavras, a historicidade do imaginário (MAIA, 2011). Isadora Ribeiro, mestrando também por mim orientada, pesquisou as representações sociais da ruralidade brasileira na revista Globo Rural de 1985 a 2015, verificando alterações, permanências ou exclusões nestas ou destas construções simbólicas ao longo das décadas. Igualmente aí, os resultados revelaram a grande variedade de imagens antropocêntricas, tecnocêntricas e biocêntricas do mundo rural, onde a natureza tem destaque (RIBEIRO, 2017). Debate semelhante pode ser encontrado na dissertação de Danielle Ferreira Sibonis, também defendida no Posjor/Ufsc e por mim orientada, sobre as representações socioculturais dos animais no jornalismo impresso brasileiro (SIBONIS, 2015).

7 No original: "Nature also carries an immensely complex and contradictory symbolic load; it is the subject of very contrary ideologies; and is has been represented in an enormous variety of differing ways. In recente times, it has come to occupy a central place on the political agenda as a result of ecological crisis, where is figures as a general concept through which we are asked to re-think our current use of resources, our relations to other forms of life, and our place within, and responsabilities towards to the eco-system" (Soper, 2000, p. 2). 
visão antropocêntrica e, consequentemente, nossas ações dificultam nosso entendimento do que é a natureza. Até mesmo quando altamente admirada parece estar a serviço do humano. Logo, não há nada de casual na configuração das imagens de natureza produzidas e reproduzidas pela imprensa brasileira. Há responsabilidades políticas e éticas. Foi isso o que se pretendeu discutir neste estudo.

\section{Referências}

DIEGUES, Antonio Carlos S. O mito moderno da natureza intocada. São Paulo: NUPAUB - USP, 1994.

DESCOLA, Philippe. A natureza: um conceito em sursis? In: A ciência: deus ou diabo? / Guitta Passis-Pasternak (org.). São Paulo: Editora UNESP, 2001. p. 109-121.

DURAND, Gilbert. A imaginação simbólica. São Paulo: Cultrix / Edusp, 1988.

As estruturas antropológicas do imaginário: introdução à arquetipologia geral. São Paulo: Martins Fontes, 1997.

Mito e sociedade: a mitanálise e a sociologia das profundezas. Lisboa: 1983.

Mito, símbolo e mitologia. Lisboa: Presença, 1984.

HEINBERG, Richard. Memórias e visões do paraíso; explorando o mito universal de uma idade do ouro perdida. Rio de Janeiro: Campus, 1991.

HOUDAYER, Hélène. Pensar o universo natural a partir dos regimes da imagem. 0 pensamento de Gilbert Durand. Revista Famecos, Porto Alegre, v. 24, n. 3, set./ dez. 2017.

LEGROS, Patrick e outros. Sociologia do imaginário/Frédric Monneyron, Jean-Bruno Reanrd, Patrick Legros e Patrick Tacussel. Porto alegre: Sulina, 2007.

LENOBLE, Robert. História da ideia da natureza. Lisboa: Edições 70, 1990.

MAFFESOLI, Michel. Elogio da razão sensível. Rio de Janeiro: Vozes, 1998.

O imaginário é uma realidade (entrevista). Revista Famecos, (Porto Alegre), v. 1, n. 15, p. 74-82, ago. 2001.

MAIA, Flávia Dourado. O jornalismo entre o efêmero e o eterno: imaginário e natureza na Globo Rural (1985-2010). 2011. 171f. Dissertação (Mestrado em Jornalismo) Programa de Pós-Graduação em Jornalismo, UFSC, Florianópolis, SC, 2011.

PITTA, Danielle Perin Rocha. Iniciação à teoria do imaginário de Gilbert Durand. Rio de Janeiro: Atlântica, 2005. 
SCHAMA, Simon. Paisagem e memória. São Paulo: Cia das Letras, 1996.

SHELDRAKE, Rupert. O renascimento da natureza: o reflorescimento da Ciência e de Deus. São Paulo: Cultrix, 1997.

SILVA, Juremir Machado. As tecnologias do imaginário. Porto Alegre: Sulina, 2006.

SILVA, Gislene. Imaginário coletivo: estudos do sensível na teoria do jornalismo. Revista Famecos, Porto Alegre, v. 17, n. 3, p. 244-252, set/dez. 2010.

Jornalismo e construção de sentido: pequeno inventário. Estudos em Jornalismo e Mídia, Florianópolis, ano II, n .2, p. 95-107, dez. 2005.

O sonho da casa no campo: jornalismo e imaginário de leitores urbanos. Florianópolis: Insular, 2009.

SILVA, Gislene; MAIA, Flávia Dourado. Sobre a perspectiva dominante nos estudos da dimensão simbólico-mítica das notícias. Revista Galáxia, São Paulo, v. 21, p. 113-224, jun. 2011.

SOPER, Kate. What is nature? Oxford: Blackwell, 2000.

THOMAS, Keith. $\mathbf{O}$ homem e $\mathbf{0}$ mundo natural: mudanças de atitude em relação às plantas e aos animais (1500-1800). São Paulo: Cia. das Letras, 1988.

WILLIAMS, Raymond. 0 campo e a cidade: na história e na literatura. São Paulo: Cia. das Letras, 1989.

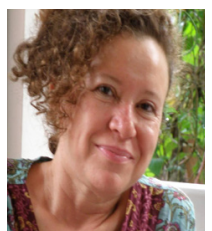

Dados da autora:

Gislene Silva | gislenedasilva@gmail.com

Universidade Federal de Santa Catarina

Pós-Doutora pela Escola de Comunicação e Artes da Universidade de São Paulo (ECA-USP) (2009) e Universidad Complutense de Madrid (2016). Professora do Programa de Pós-Graduação em Jornalismo da Universidade Federal de Santa Catarina (PPGJOR-UFSC) e Líder do Grupo de Pesquisa Crítica de Mídia e Práticas Culturais.

Endereço da autora:

Programa de Pós-Graduação em Jornalismo da Universidade Federal de Santa Catarina

Campus Universitário, $\mathrm{s} / \mathrm{n}^{\circ}$ - Trindade

88.040-970 - Florianópolis (SC) - Brasil 